Olgu Sunumu/Case Report

\title{
Farklı bir göğüs ağrısı nedeni: Spontan pnömomediastinum
}

\author{
A different cause of chest pain: Spontaneous pneumomediastinum
}

Hızır Ufuk Akdemir*, Türker Yardan, Ahmet Baydın, Ali Kemal Erenler

Ondokuz Mayıs Üniversitesi, Tip Fakültesi, Acil Tıp AD, Samsun

\begin{tabular}{|c|c|}
\hline MAKALE BİLGÍLERİ & ÖZET \\
\hline Makale & \multirow{4}{*}{$\begin{array}{l}\text { Pnömomediastinum (PM) mediasten içinde hava bulunmasıdır. Spontan pnömomediasti- } \\
\text { num (SPM) nadiren semptom verir ve genellikle tesadüfen saptanır. SPM daha çok genç er- } \\
\text { keklerde görülen ve genellikle kendi kendine iyileşme eğilimi gösteren bir klinik durumdur. } \\
\text { Klinik çok değişkendir ve müphem şikayetlerden hayatı tehdit eden solunum yetmezliğine } \\
\text { kadar ilerleyebilir. Ağrı, en sık görülen semptomdur (\%80-90) ve substernal bölgeye loka- } \\
\text { lize olur. PM tanısı radyolojik olarak standart PA ve yan akciğer grafisi ile konur. Tedavi } \\
\text { sebebe yönelik olup hızla tanı konularak gerekiyorsa erken cerrahi tedavi yapılmalıdır. Biz } \\
\text { bu yazımızda, acil servise göğüs ağrısı ile başvuran bir olguyu sunarak, göğüs ağrısına } \\
\text { neden ayırıcı tanısında SPM'a dikkat çekmeyi amaçladık. } \\
\text { J. Exp. Clin. Med., 2010; 27: 77-80 }\end{array}$} \\
\hline $21 / 10 / 2009$ & \\
\hline Kabul & \\
\hline $\begin{array}{l}\text { * Yazışma Adresi: } \\
\text { Hızır Ufuk Akdemir } \\
\text { Ondokuz Mayıs Üniversitesi,Tıp Fakültesi, } \\
\text { Acil Tıp AD, Kurupelit, Samsun } \\
\text { e-posta: hufukakdemir@hotmail.com }\end{array}$ & \\
\hline
\end{tabular}

\section{Anahtar Kelimeler: \\ Göğüs Ağrısı \\ Akciğer Grafisi \\ Ayırıcı Tanı \\ Spontan Pnömomediastinum \\ Acil Servis \\ Genç Erkek}

Key Words :

Chest Pain

Chest X-Ray

Differantial Diagnosis

Spontaneous Pneumomediastinum

Emergency Department

Young Man

\begin{abstract}
Pneumomediastinum (PM) is a term given to the situation when there is air in the mediastinum. Spontaneous pneumomediastinum (SPM) gives symptom rarely and it is diagnosed coincidentally. SPM is seen frequently in young males and tend to heal spontaneously. Clinical appearance is unsteady spreads from ambiguous complaints to respiratory insufficiency which threatens life. Pain is the most common symptom and is localized substernally. PM is diagnosed by PA and lateral chestlung X-ray radiologically. Treatment must be based on cause and early surgical interventionery must be performed if needed. In this article, we aimed to present a case that has been admitted to Emergency Department for chest pain and point to SPM in the differential diagnosis of chest pain.

J. Exp. Clin. Med., 2010; 27: 77-80
\end{abstract}

(C) 2010 OMÜ Tüm Hakları Saklıdır.

\section{Giriş}

Pnömomediastinum (PM) mediasten içinde gaz ya da serbest havanın bulunması olarak tanımlanmaktadır. Pnömomediastinum travmatik ve spontan olarak iki şekilde meydana gelebilir. Travmatik pnömomediastinum sıklıkla künt göğüs travması, kafa travması, trakeostomi, endoskopi-bronkoskopi sonrası (özofagus perforasyonu, trakeobronşial yaralanma) ve mekanik ventilasyona bağ $l_{1}$ olarak görülmektedir (Lopez ve Roldan, 2001). Spontan pnömomediastinum (SPM) ise spesifik bir etiyolojik faktör olmaksızın daha çok genç hastalarda görülen ve genellikle kendiliğinden iyileşme gösteren bir klinik tablodur (Lopez ve Roldan, 2001; Olgun ve ark., 2009).
Pnömomediastinumda klinik çok değişken olup masum yakınmalardan hayatı tehdit eden solunum yetmezliğine kadar değişiklik gösterebilmektedir. Pnömomediastinumda göğüs ağrısı en s1k görülen yakınma olup genellikle substernal bölgededir. Ağrı dişında yutma güçlügü̈, boğazda takılma hissi, ses kısıklığı ve salivasyonda artış görülebilen diğer yakınmalardır (Demirel ve ark., 2008). Hastalarda fizik muayenede boyun venlerinde dolgunluk, cilt altı amfizem, Hamman belirtisi (göğüs ön yüzünün oskültasyonu sırasında kalp tepe atımıyla senkronize çıtırtı sesinin duyulmas1), siyanoz ve takipne saptanabilir, hatta ilerlemiş olgularda kardiyovasküler kollaps olabilir (Işık ve ark., 2005). Biz bu yazımızda, acil servise göğüs ağrısı 
ile başvuran bir olguyu sunarak, göğüs ağrısının ayırıcı tanısında SPM'a dikkat çekmeyi amaçladık.

\section{Olgu}

Yirmi yaşında erkek hasta, acil servise sol kolunda ve göğsünde ağrı yakınması ile başvurdu. Hastadan, gögüs ağrısının yaklaşık sekiz saat önce aniden, bıçak saplanır tarzda başladığ ve göğsünün sol tarafına lokalize olduğu öğrenildi. Hasta göğüs ağrısının nefes alıp vermekle arttığını ifade ediyordu. Hastanın özgeçmişinde tanı konulmuş herhangi bir özellik yoktu.

Fizik muayenede kan basinc1: 110/70 $\mathrm{mmHg}$, nabız: 104 /dakika, solunum: 20 /dakika, ateş: $36,7^{\circ} \mathrm{C}$ idi. Genel durumu orta, bilinci açık idi. Hastanın dinlemekle kalp ve solunum seslerinin normal olduğu saptand. Hastada siyanoz, Hamman bulgusu, cilt altı amfizemi ve krepitasyonu saptanmadi.

Laboratuar bulgularında beyaz küre sayısı 13500/ $\mathrm{uL}$ idi ve diğer tüm parametreler normaldi. Hastanın çekilen EKG' sinde kalp hızı 100/dakika ve sinüs ritminde idi. Acil serviste bakılan ilk arteryal kan gazında $\mathrm{pH}$ : 7.4, pCO2: $32 \mathrm{mmHg}$, pO2: $91 \mathrm{mmHg}$ ve oksijen satürasyonu: \%98 idi. Arka-ön (PA) akciğer grafisinde sol akciğer hilusuna komşu alandan başlayıp, sol ventrikül duvarına paralel olarak diyafragmanın soluna doğru uzanan pnömomediastinum ile uyumlu lineer hava dansitesi görüldü, cilt altı amfizemi, pnömotoraks ve/veya hemotoraks izlenmedi (Şek. 1, 2).

PM tanısı konulan hastadan ileri tetkik amaciyla boyun ve gögüs bilgisayarlı tomografisi (BT) istendi. Çekilen tomografide mediastende yaygın hava değerlerinin bulunduğu ve bu hava değerlerinin boyuna doğru da uzanım gösterdiği saptandı (Şek. 3, 4). BT'de mediastendeki hava değerleri dişında ek bir patoloji saptanmayan hasta göğüs cerrahisi ile konsülte edildi ve göğüs cerrahisi servisine yatırılarak takibe alınd. Hastanın takibinde oral alım kesildi, antibiyotik ve sıvı tedavisi başlandı. Hastanın takibi sırasında herhangi bir komplikasyon gelişmedi ve bir hafta sonra şifa ile taburcu edildi.

\section{Tartışma}

Pnömomediastinum'un fizyopatolojisi ilk olarak Macklin tarafından 1944 yılında tanımlanmıştır. Macklin PM'un artmış intraalveolar basınca bağlı olarak terminal alveollerin yırtılması sonucunda oluştuğunu ve bu yırtıktan havanın basınç farkına bağlı olarak akciğer parankiminden mediastene doğru yayıldığını bildirmiştir (Koullias ve ark., 2004). Chalumeau ve ark. PM'de klinik bulguların alveollerden kaçan hava miktarı ile ilişkili olduğunu bildirmişlerdir. PM'da hava miktarı arttıkça yaygın cilt altı amfizemi, hava yollarına bası ve solunum yetmezliği gibi komplikasyonlar görülebilir (Chalumeau ve ark., 2001). Jougon ve ark., yaptıkları çalışmalarında Spontan

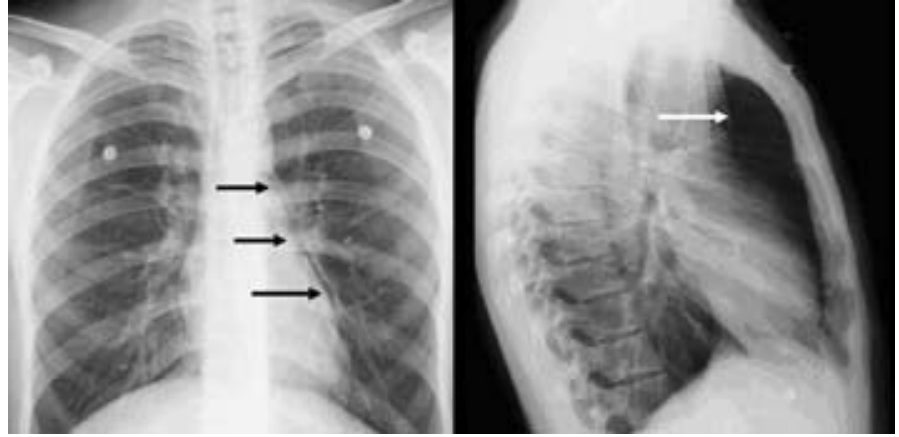

Şek. 1-2: Posterior-anterior ve yan akciğer grafisinde pnömomediastinum görüntüsü.

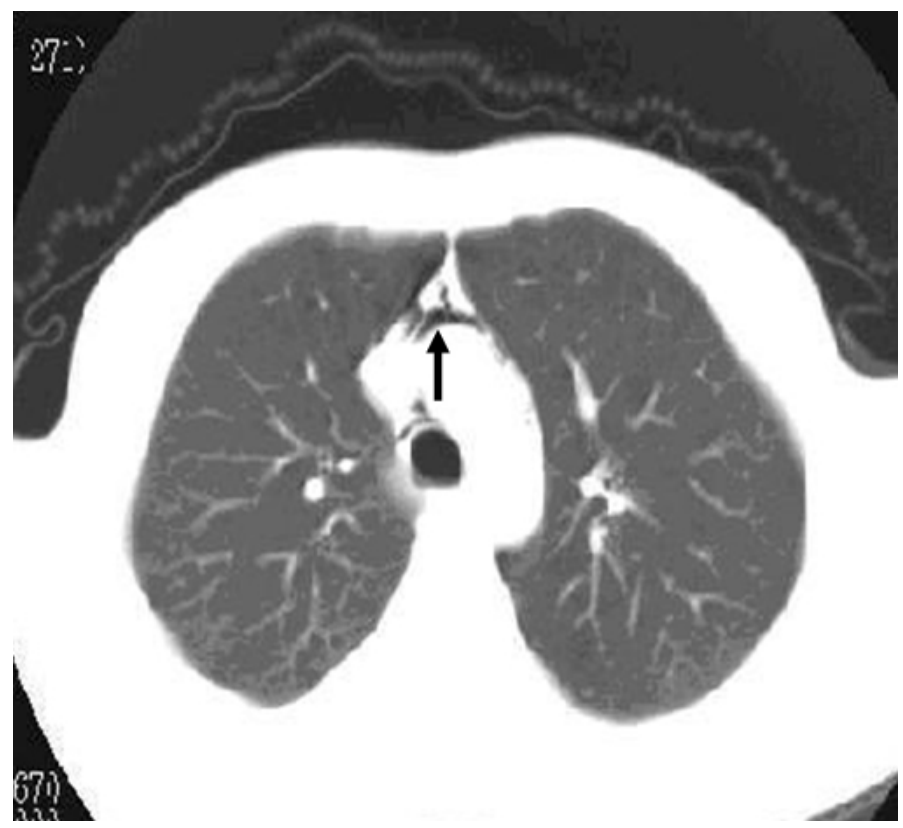

Şek. 3: Gögüs bilgisayarlı tomografide pnömomediastinum görüntüsü

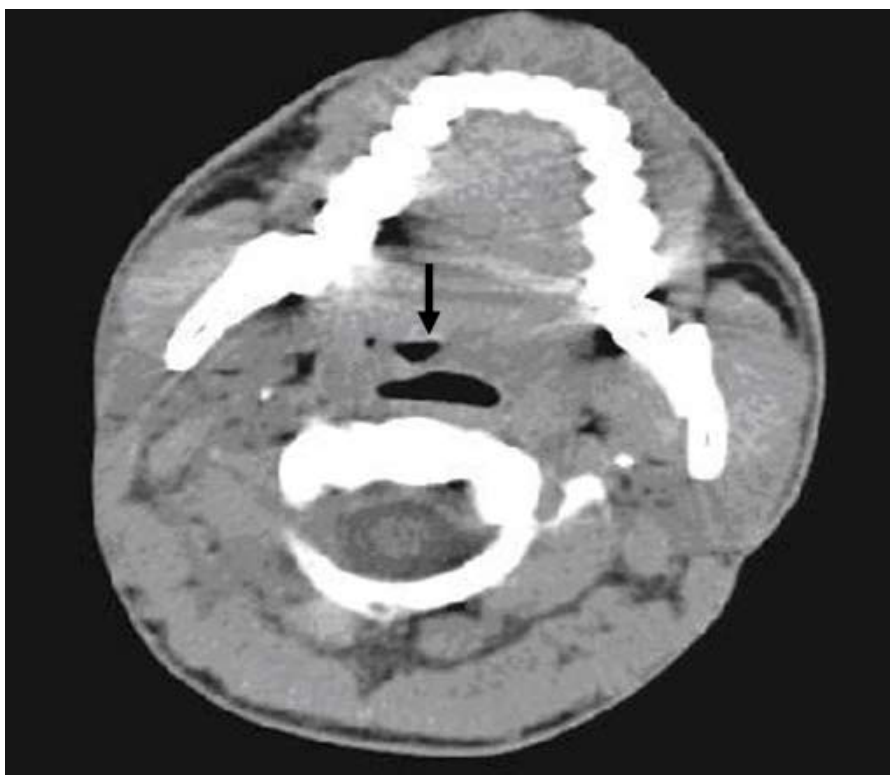

Şek. 4: Boyun BT’de trakea etrafinda serbest hava görüntüsü

pnömomediastinum'lu hastaların genellikle ani gelişen nefes darlı̆̆ 1 , boyunda şişme, öksürük ve nadiren yutma güçlüğü ile hastaneye başvurduklarını bildirmişlerdir (Jougon ve ark., 2003). Bizim olgumuz ise farklı olarak sol kolunda ve göğüs ağrısı yakınması ile acil servise başvurmuştu.

Spontan pnömomediastinum özellikle genç erkeklerde görülen, çoğunluğu semptomsuz olan, semptomatik 
olanlarda ise semptomların genellikle kendiliğinden gerilediği nadir bir klinik durumdur ve bu olguların \%30'unda herhangi bir neden bulunamamaktadır (Chalumeau ve ark., 2001; Chujo ve ark., 2006). Bu hastalarda fizik muayene tamamen normal olabileceği gibi takipne, siyanoz, juguler venöz dolgunluk ve cilt altı amfizem gibi anormal bulgular da olabilir ve hatta tipik bulgusu olan Hamman belirtisi de saptanabilir (Abolnik ve ark., 1991; Bilgin ve ark., 2003; Demirel ve ark., 2008). Olgumuz genç bir erkekti ve yaptığımız ileri tetkiklerde pnömomediastinuma neden olacak herhangi bir sebep saptayamadık. Olgumuzun aynı zamanda olgumuzun fizik muayenesi tamamen normaldi.

Pnömomediastinum için cilt altı amfizemi patogonomonik olmasa da, varlığının göğüs boşluğu içerisinde serbest havanın bulunduğuna işaret ettiği bildirilmektedir (Iş1k ve ark., 1989). Cilt altı amfizeminin PM için pozitif prediktif değerinin \%100 olduğu da rapor edilmiştir (Stack ve ark., 1996). Bizim olgumuzda mediastende serbest hava bulunmasına rağmen cilt altı amfizemi yoktu.

Klinik olarak mediastinal amfizeme ateş, hipotansiyon ve lökositoz eşlik edebilir (Bilgin ve ark., 2003; Flynn ve ark., 1989). Bizim olgumuzda lökositoz mevcuttu fakat ateş ve hipotansiyon bulunmamaktaydi. PM olgularında görülen EKG değişiklikleri; voltaj düşüklügü, nonspesifik aks değişikliği, lateral prekordiyal derivasyonlarda ST/T dalgası değişiklikleri ve ST yükselmesi şeklinde olabilmektedir (Işı ve ark., 2005). Olgumuzun çekilen EKG'sinde taşikardi dışında herhangi bir değişiklik görülmedi.

Pnömomediastinum tanıs1 standart posteroanterior ve yan akciğer grafisi ile konabilmektedir (Bilgin ve ark., 2003; Iş1k ve ark., 2005; Demirel ve ark., 2008). Standart PA akciğer grafisinde genellikle sol kalp ile mediastinal plevra arasında hava bulunmaktadır (Işık ve ark., 2005). Göğüsün PA akciğer grafisinde, kalbin alt kısmında "Devam eden diyafragma işareti" bulunabilir. Bu işaretin bulunmasının PM için karakteristik olduğu bildirilmiştir (Çelebi ve ark., 2008). PM tanısında standart PA akciğer grafisinin yanı sira servikal grafiler, toraks BT, bronkoskopi ve özofagoskopiden de yararlanılabilir. Toraksın BT incelemesi PM tanısında en duyarlı tanısal yöntemdir (Iş1k ve ark., 2005). Mediastende genişleme ve hava kabarcıklarının görülmesi tanıyı doğrular. Yapılan radyolojik tetkik ve incelemelerde cerrahi işlem gerektirecek herhangi bir patoloji saptanmazsa, tedavi yaklaşımı çoğunlukla koruyucu ve destek amaçlı olması gerektiği bildirilmiştir (Bilgin ve ark., 2003; Işı1k ve ark., 2005).

Tedavi nedene yönelik olup hızla tanı konulmalı ve gerekiyorsa erken cerrahi tedavi yapılmalıdır (Demirel ve ark., 2008). Bu hastaların izlem süreleri en az 24-36 saat olmalıdır (Bilgin ve ark., 2003; Demirel ve ark., 2008). Bu izlem süresi hastanın klinik durumuna göre uzatılabilir. Komplike olmayan PM'li olgularda; istirahat, analjezik ve Valsalva manevrasından kaçınarak spontan rezolüsyon beklenir (Altınok ve ark., 2007). Hastaların gelişebilecek ciddi komplikasyonlara karşı monitörize edilip yakın takibe alınması önerilmektedir (Altınok ve ark., 2007). Genellikle 48 saat içinde kendiliğinden gerileme gösteren bu klinik tabloda, hastanın nefes darlığ 1 şiddetli ise oksijen desteği yapılmalıdır (Demirel ve ark., 2008). Hastalara mediastinit gelişimini engellemek için intravenöz antibiyotik tedavisi başlanabilir (Bilgin ve ark., 2003). Takibe alınan hastaların oral beslenmesi kesilir. Takip sürecinde hastalar günlük fizik muayeneleri yapılarak göğüs radyografileri ile izlenirler. Takipte hastaların semptomlarının hızla gerilediği görülür ve klinik olarak stabil olan hastalar taburcu edilebilir (Ralp-Edwards ve Pearson, 1994; Bilgin ve ark., 2003). Olgumuzda oral beslenme kesildi, günlük fizik muayenesi ve radyolojik incelemesi yapıldı. Takibinde semptomları gerileyen, beyaz küre değerleri düşen ve klinik olarak stabil hale gelen hasta yatışının yedinci gününde taburcu edildi.

\section{Sonuç}

SPM özellikle genç erkeklerde görülen ve semptomların genellikle kendiliğinden gerilediği nadir bir klinik durumdur. Klinikte ani başlayan göğüs ağrısı, nefes darlığı, siyanoz, boyun venlerinde dolgunluk, disfaji, boğazda takılma hissi, disfoni, ateş ve hipotansiyon görülebilir. Tanı fizik muayene ve göğüs radyolojik incelemesiyle konur. Ayırıcı tanıda kas-iskelet sistemi kaynaklı ağrılar, plevral, pulmoner, kardiyak ve özofageal sebepler düşünülmelidir. Eğer sebep özefagus rüptürü ise morbidite ve mortalite yüksektir. SPM tedavisi konservatif ya da cerrahi olabilir. Özellikle acil servise gögüs ağrısı ile başvuran genç erkeklerin ayırıcı tanısında SPM düşünülmelidir.

\section{KAYNAKLAR:}

Abolnik, I., Lossos, I.S., Breuer, R., 1991. Spontaneous pneumomediastinum; a report of 25 cases. Chest. 100, 93-95.

Akay, H., Enön, S., 2006. Mediasten amfizemi. Türkiye Klinikleri J. Surg. Med. Sci. 2,65-68.

Altınok, T., Ceran, S., 2007. Pnömomediastinum. Türkiye Klinikleri J. Surg. Med. Sci. 3,39-42.

Bilgin, M., Kahraman, C., Akçalı, Y., 2003. Spontan pnömomediastinum. Toraks Dergisi. 4, 183-185.

Chalumeau, M., Le Clainche, L., Sayeg, N., 2001.Spontaneous pneumomediastinum in children. Pediatr. Pulmonol. 31, 67-75.

Chujo, M., Yostimatsu, T., Kimura, 2006. Spontaneous pneumomediastinum. Kyobu Geka. 59, 464-468.

Çelebi, S., Yazıcı, Z., Hacımustafaoğlu, M., 2008. Radyolojik değerlendirme(X-ray evaluation). J. Pediatr. Inf. 2, 40-41.

Demirel, A., Aynac1, E., Özgül, M.A., 2008. Primer spontan pnömomediastinum. Solunum 10, 71-73.

Flynn, A.E., Verrier, E.D., Way, L.W., 1989. Esophageal perforation. Arch. Surg. 124, 1211-1215.

Işık, A.F., Kurnaz, M., Çobanoğlu, U., 2005. Göz travması sonrası gelişen pnömomediastinum. Türk Göğüs Kalp Damar Cer. Derg. $13,177-178$.

Jougon, J.B., Ballester, M., Delcombre, F., 2003. Assesment of spontaneous pneumomediastinum: experience with 12 patients. Ann. 
Thorac. Surg. 75, 1711-1714.

Koullias, J.G., Korkolis, D.P., Wong, X.J., 2004. Current assessment and management of spontaneous pneumomediastinum; experience in 24 adult patients. Eur. J. Cardiothorac. Surg. 25, 852-855.

Lopez, M.F., Roldan, J.S., 2001. Cervical emphysema, pneumomediastinum, and pneumothorax following self-induced oral injury. Chest. 120, 306-309.

Olgun, H., Türkyılmaz, A., Aydın, Y., 2009. Spontaneous pneumomediastinum in a child as a rare cause of chest pain. Türk Kardiyol. Dern. Arş. 37, 51-52.

Ralp-Edwards, A.C., Pearson, F.G., 1994. Atypical presentation of spontaneous Pneumomediastinum. Ann. Thorac. Surg. 58, 17581760.

Stack, A.M., Caputo, G.L., 1996. Pneumomediastinum in childhood asthma. Pediatr. Emerg. Care. 12, 98-101. 